\title{
Carbon Nanotubes as Superior Sorbent for Removal of Phenol from Industrial Waste Water
}

\author{
C.E. El shafiee ${ }^{1 *}$, M.O. Abdel-salam ${ }^{1}$, S.M.N. Moalla ${ }^{2}$, H.R. Ali ${ }^{1}$, Doaa I. Osman ${ }^{1}$ \\ R.I. Abdallah', Y.M. Moustafa ${ }^{1}$ \\ ${ }^{1}$ Egyptian Petroleum Research Institute. P.o. Box 11727, Nasr City, Cairo, Egypt. \\ ${ }^{2}$ Chemistry Department, Faculty of Science, Port said University, Port said, Egypt.
}

RGANIC pollutant substances have direct effect on humans and animals. Wastewater
containing organic pollutant like phenol compound can contaminate ground water
resource and thus lead to a serious ground water problem. This study presents the adsorption
technique of (MWCNt) which is used as adsorbents for the removal of phenol compounds from
synthetic contaminated water. Many parameters are studied like pH, agitation speed, contact
time and adsorbent concentration to determine their influence on the removal of phenol and on
adsorption rate.The concentration of phenol in water before and after treatment was determined
(analyzed) using high performance liquid chromatography technique (HPLC). The kinetic
studies for adsorption followed the pseudo-second order model. The adsorption isotherm fits
with Langmuir isotherm. The optimum conditions using MWCNTs were contact time 120 min,
pH 7 , agitation speed 130 rpm and dose of adsorbent $0.3 \mathrm{~g}$. The removal percentage was $85.54 \%$.

Keywords: Carbon nanotubes, Adsorbent materials, Phenolic compounds, Industrial waste water, Agitation, Kinetic adsorption.

\section{Introduction}

Environmental pollution is now one of the important problems facing humanity which increased rapidly in the last few years and reached frightening level because of its bad effect on human beings and animals. One of these problems is water pollution which is serious and continual problem all over the world [1].

Phenolic compounds are supposed to be risky wastes, which are released into water by industries such as chemical, pharmaceutical, petroleum refineries, gas, coke manufacturing and pesticide. These industries have bad side effect, which cause contamination of water, this contamination affects both aquatic life and human health [2].

Phenol is widely used in petrochemical, leather, plastic, pharmaceutical, oil refining and pesticide industries [3-6]. It is slightly acidic, noticeably soluble in water and also considered one of the main pollutants in waste water, [7] since it is toxic to organisms even at low concentration and is hard to be biodegraded; therefore rigid limits set on the levels which are acceptable for phenol in waste water.

Different methods are used to remove phenol from aqueous solutions [8], like chemical degradation [9], biological degradation [10] and adsorption [11]. From these available methods, adsorption is the effective process for removing the environmental pollutants [11].

Recently, synthesized nano-sized adsorbents like carbon nanotubes have been extensively used as adsorbents to remove toxic pollutants from aqueous media.

In recent years, carbon nanotubes (CNTs) have been extensively used as promising applicants in many nano-technological fields, including efficacious adsorbents for removal of contaminants [12-15]. Specifically, CNTs could significantly adsorb organic contaminants because of their strong affinities [16-19].

\footnotetext{
*Corresponding author e-mail: niceangel_111@hotmail.com, Tel:+201061788893, Fax: + (202)22747433. DOI: 10.21608/EJCHEM.2017.1756.1149 
There are two types of carbon nanotubes according to their structural formation: singlewalled carbon nanotubes "SWNT" which has one layer only of graphene sheet and Multiwalled carbon nanotubes "MWNT" which has multiple layers of graphene sheet [20]. Herein, the major objective of this study was to achieve an understanding of the adsorption technique of MWCNTs in the removal of phenol from industrial waste water by examining the influence of different parameters on the adsorption process. Additionally, adsorption kinetics and adsorption isotherms were investigated.

\section{Material and Methods}

\section{Materials}

Sodium hydroxide (98\%) and hydrochloric acid (98\%) were purchased from Sigma Aldrich. Sulfuric acid (97\%) and nitric acid (98\%) were obtained from Fluka. Carbon nano tubes purchased from Egyptian Petroleum Research Institute (EPRI )which is used as adsorbents for studying the characteristics of adsorption of phenol from waste water.

\section{Method}

Purification of carbon nanotubes (MWCNTS)

The purification process of CNTs was achieved by chemical oxidation method. Specific amount of carbon nanotubes were mixed with mixture of concentrated nitric acid / sulfuric acid (3:1 by volume, respectively). The mixture was refluxed at $120{ }^{\circ} \mathrm{C}$ for $4 \mathrm{~h}$ in oil bath, left to cool at room temperature, diluted with deionized water and then filtered by filter paper. This washing process was repeated many times and the mixture was dried overnight at $100^{\circ} \mathrm{C}[21]$.

\section{Adsorption procedure}

This study was carried in a batch system, batch adsorption was performed in $50 \mathrm{ml}$ flasks inside an incubator container with a constant temperature. A magnetic stirrer with a fixed setting was used to mix thoroughly all contents of all flasks in a constant speed. Firstly $50 \mathrm{ml}$ of stock solution was added into an Erlenmeyer flask, $0.1 \mathrm{~N} \mathrm{Hcl}$ and $0.1 \mathrm{~N} \mathrm{NaOH}$ were used to adjust $\mathrm{pH}$, after that the adsorbent was put in the Erlenmeyer flask for shaking in a regulated speed, different adsorption times and adsorbent doses were considered. After the adsorption, the samples were filtrated and the concentration of phenol was determined using HPLC. The adsorption process was studied as initial phenol concentration ( 5 to $45 \mathrm{mg} / \mathrm{L}$ ), function of $\mathrm{pH}$ (3 to 10 ), adsorbent dose (10 to

Egypt. J. Chem. 61, No. 1 (2018)
$500 \mathrm{mg} / \mathrm{L})$, agitation speed $(50-200)$ and contact time (30 to $1080 \mathrm{~min}$ ).

By using transmission electron microscopy (HR-TEM) morphological features of adsorbent can be determined. The phase structure and purity of crystal were analyzed using X-ray diffraction (XRD). A thermo gravimetric analyzer (TGA) was used to examine the thermal stability up to $1200^{\circ}$ $\mathrm{C}$ in nitrogen atmosphere with a steady rate $5^{\circ} \mathrm{C} /$ min. Zeta potential was measured using Zeta sizer (ZS). The dynamic light scattering spectroscopy (DLS) was used to measure relative hydrodynamic diameter distribution of MWCNTs and composites.

\section{Results and Discussion}

MWCNTs specifications

\section{TEM and DLS Analysis}

The HR-TEM image of MWCNTs is shown in Fig. 1 from this figure, it can be seen that the diameter of nano-sized tubes is about $20 \mathrm{~nm}$ in diameter, which is confirmed that it is MWCNTs, because the tube diameter of MWCNTs varied from 4 to $150 \mathrm{~nm}$ [22]. The curve of DLS (Fig. 2) shows that the diameter of MWCNTs is less than $100 \mathrm{~nm}$.

\section{$X$-Ray analysis}

Figure 3 shows XRD pattern of MWCNTs, in this fig. there are two sharp peaks which are found at 26 and 42 and they are symmetric with the standard card (00-058-1638) of carbon nanotubes. This confirmed the hybridization of $\mathrm{sp}^{2}$ atoms and the concentric cylindrical behavior for the structure of carbon nanotubes [23].

\section{$T G A$}

The thermal stability of MWCNTs was examined by the thermo gravimetric analysis. Figure 4 shows that the high thermal stability of MWCNTs is up to $800^{\circ} \mathrm{C}$. The low observed loss up to $800^{\circ} \mathrm{C}$ is associated with the thermal degradations of the thermally unstable functional groups such as carboxylic and hydroxyl groups that formed on the MWCNTs during the acid purifications [24]. After that, MWCNTs are completely decomposed at around $1000^{\circ} \mathrm{C}$ in one stage thermal degradation.

\section{FTIR}

The FTIR spectra of MWCNTs are shown in Fig. 5. The peaks at $3445 \mathrm{~cm}^{-1}$ and $1136 \mathrm{~cm}^{-1}$ are assigned to the $-\mathrm{OH}$ stretching vibration and distorting vibration, respectively, which are resulting from the hydroxyl groups on the surface of the functionalized MWCNTs. The peak at 1628 $\mathrm{cm}^{-1}$ is assigned to the stretching vibration of $\mathrm{C}=\mathrm{O}$. 


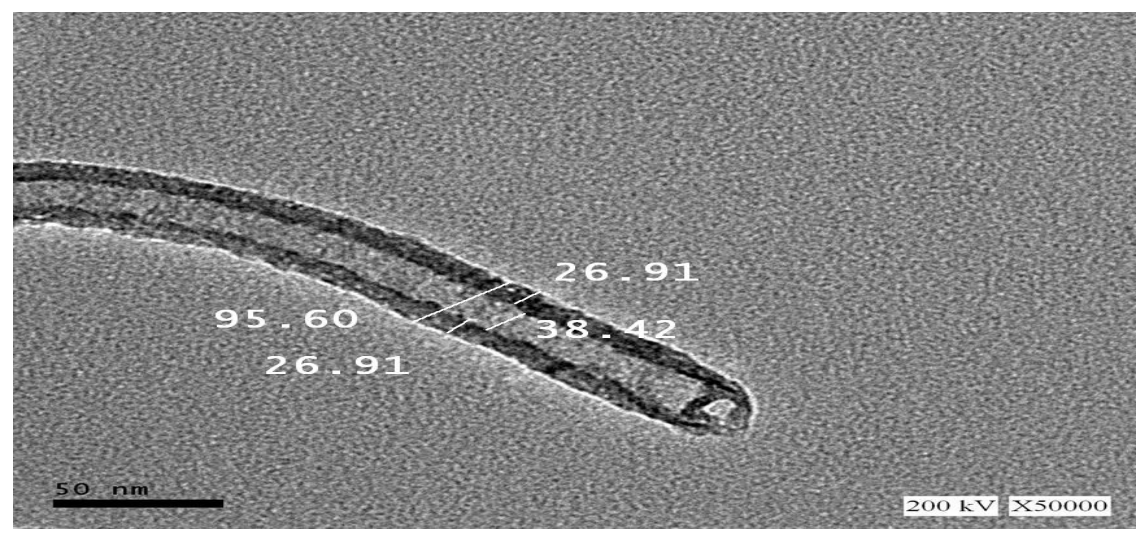

Fig. 1. HR-TEM image of MWCNTs

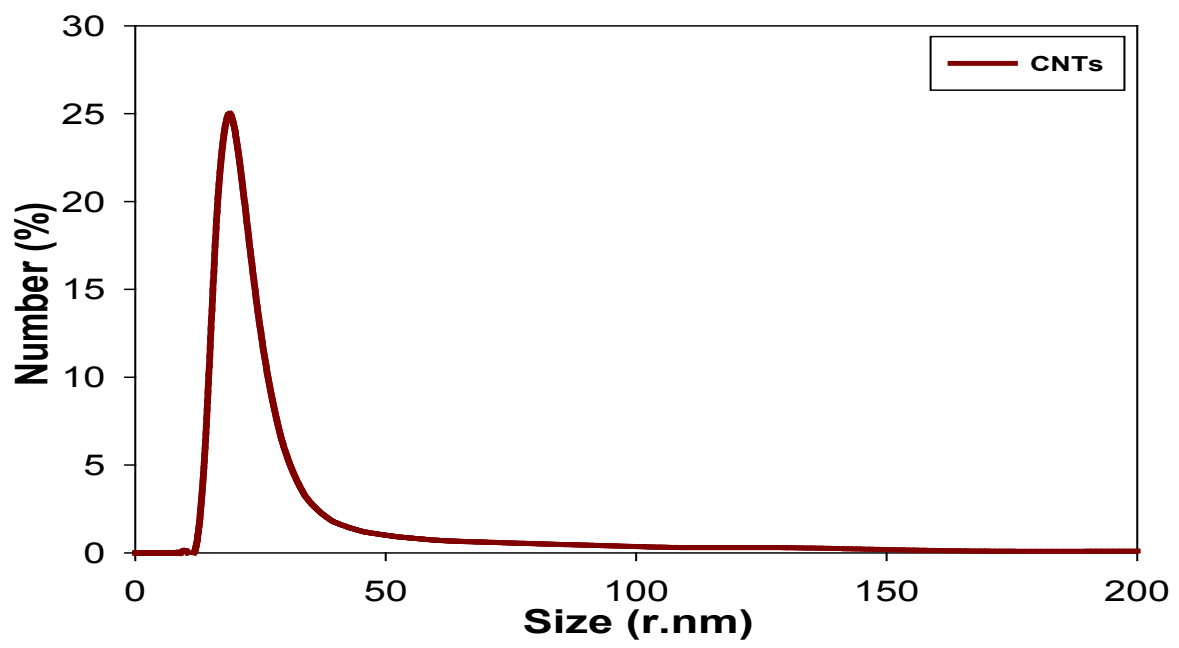

Fig. 2. DLS of CNTs.

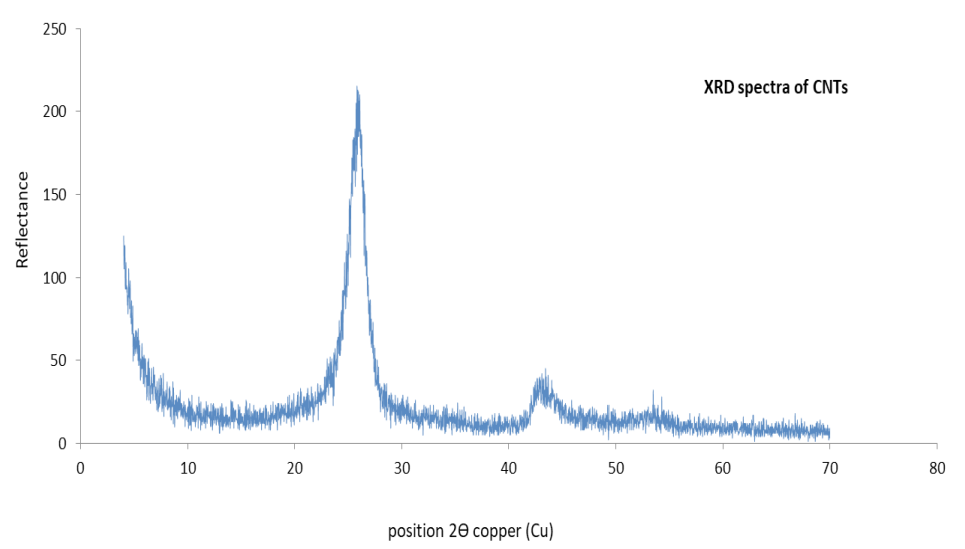

Fig. 3. XRD spectra of CNTs. 


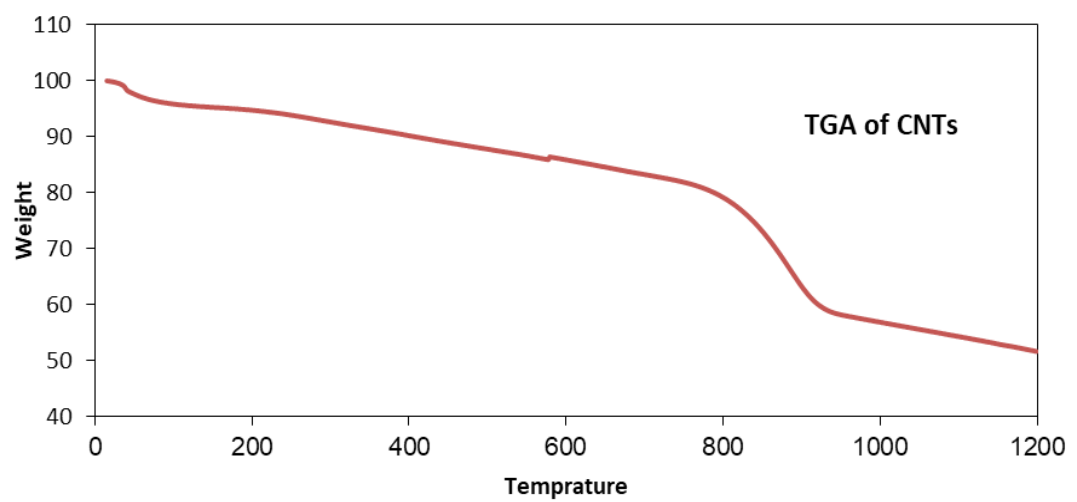

Fig. 4. TGA of CNTs.

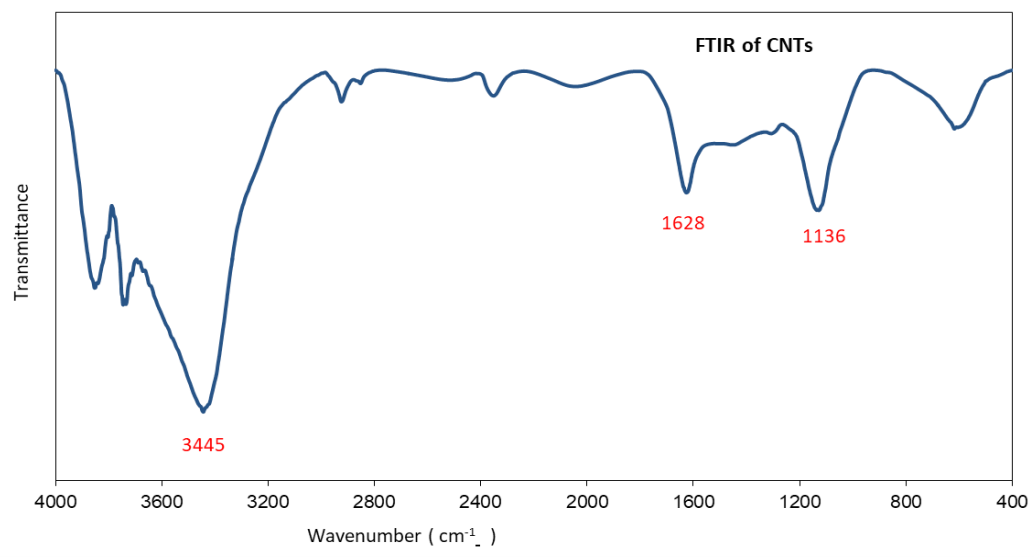

Fig.5 FTIR of CNTs.

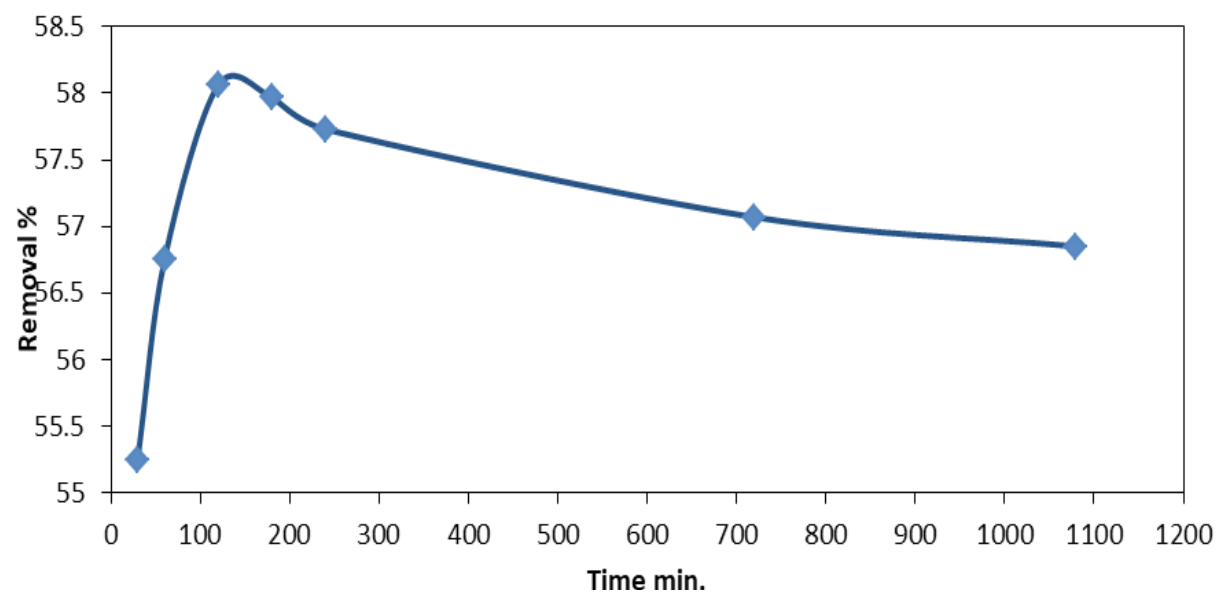

Fig. 6. The effect of contact time (min) on the adsorption of phenol. 


\section{Effect of contact time}

The contact time had a noticeable effect on the removal of phenol. To show the effect of contact time, the concentration of phenol was $25 \mathrm{ppm}$, the adsorbent dosage was $0.3 \mathrm{~g}$. The samples were withdrawn from 30 to $1080 \mathrm{~min}$ shaking period with agitation speed $90 \mathrm{rpm}$ and $\mathrm{pH} 7$. The residual concentration of phenol in solution was tested by HPLC. The adsorption capacity of phenol at various contact time is shown in Fig.6. It is clear that the adsorption capacity and removal efficiency of phenol increased with contact time till 120 min and then decreased till reach equilibrium. Which is due to the presence of abundant initial number of active sites on the sorbents, while by increasing time, the process of sorption becomes less effective due to gradually increased occupancy of these sites.

\section{Adsorption kinetics models}

A certain amount of adsorbent $(300 \mathrm{mg})$ was added to $1 \mathrm{~L}$ of phenol aqueous solution $(25 \mathrm{mg} / \mathrm{L})$. The concentration of phenol was determined by high performance liquid chromatography technique (HPLC). The pseudo - first -order kinetics and pseudo - second - order kinetics were used to estimate the sorption kinetics and calculate the sorption rates, the sorption rate constants and adsorption capacities.

The pseudo - first - order kinetic model [25] illustrates adsorption of liquid - solid manner which is based on the capacity of solid. The model can be expressed by the following equation:

$$
\log (q e-q t)=\log q e-k a 1 t / 2.303
$$

The pseudo-second-order kinetic model [26] based on the hypothesis of chemical adsorption. This type comprises all steps of adsorption. The equation for this model is as the following:

$$
\mathrm{t} / \mathrm{qt}=1 / \mathrm{ka} 2 \mathrm{qe} 2+\mathrm{t} / \mathrm{qe}
$$

where ka1 and ka2 are the adsorption rate constant, qe in $(\mathrm{mg} / \mathrm{g})$ is the equilibrium adsorption uptake of a certain adsorbent, and $\mathrm{qt}$ in $(\mathrm{mg} / \mathrm{g})$ is the adsorption uptake at time $t$. So, we can determine the values of ka1, ka2 and qe experimentally by plotting $\log (\mathrm{qe}-\mathrm{qt})$ vs. $\mathrm{t}$, reading out values from least squares analysis of intercept and slope and replacing into equation.

The kinetic equations of pseudo - first - order and pseudo - second - order are shown in Fig. 7,8 respectively, these figures clarified that the adsorption of phenol approbates better with the kinetic equation of pseudo - second - order as summarized in Table 1.

\section{Adsorption isotherm}

Adsorption isotherm describes the relation between the quantity of adsorbate which is adsorbed by the adsorbent ( $\mathrm{qe}, \mathrm{g} / \mathrm{g}$ ) and the concentration of adsorbate which is remaining in the solution after the process of adsorption reached the equilibrium at certain temperature (ce $\mathrm{mg} / \mathrm{L}$ ) . Freundlich and Langmuir equations [27] are commonly used isotherms to demonstrate solid - liquid adsorption system.

Freundlich isotherm is expressed in the following equation:

$$
\log \mathrm{qe}=1 / \mathrm{n} \log \mathrm{ce}+\log \mathrm{kf}
$$

where $\mathrm{k}$ and $\mathrm{n}$ are Freundlich constants.

Langmuir isotherm is based on monolayer adsorption hypothesis onto the homogeneous surface which has a limited number of identical sites, it can be described as follow:

$$
\mathrm{Ce} / \mathrm{qe}=1 / \mathrm{bqm}+\mathrm{ce} / \mathrm{qm}
$$

where $\mathrm{Ce}$ in $(\mathrm{mg} / \mathrm{L})$ is the solute equilibrium concentration of adsorbent in solution, qe in $(\mathrm{mg} / \mathrm{g})$ is the capacity of adsorption for specific kind of adsorbent in equilibrium case, $\mathrm{qm}$ in $(\mathrm{mg}$ / g) is the maximum adsorption capacity, and b is the constant of equilibrium adsorption .

From adsorption isotherm we can take more information about the behavior of adsorption for an adsorbent. Both equations of Langmuir and Freundlish were chosen to normalize the data of adsorption. The calculated results are listed in Table 2, and we notice that the calculated results appropriate for Langmuir model better than for Feundlich model, which indicates that the mechanism of adsorption is monolayer.

\section{Effect of $p H$}

The effect of $\mathrm{pH}$ on the efficiency of the removal of phenol using MWCNTs was illustrated in Fig.9. The pH range from 3 to 9 for 2 hours, shacking speed of $130 \mathrm{rpm}$, and dosage of adsorbent of $0.3 \mathrm{~g} / \mathrm{l}$. It is noticed that the phenol removal by MWCNTs increased continuously by increasing the $\mathrm{pH}$ from 3 to 7 and then decreased within the $\mathrm{pH}$ range from 7 to 10 . The maximum percentage removal of phenol by MWCNTs was at $\mathrm{pH}$ 7. The active sites in the adsorbent particles have negative charges. At low $\mathrm{pH}$ environment, the $\mathrm{H}^{+}$ions in this media can neutralize those

Egypt. J. Chem. 61, No. 1 (2018) 
negative particles and thus decrease the difficulty of phenol ions diffusion therefore the chances of their adsorption increase. While at high $\mathrm{pH}$ environment, there is high concentration of $\mathrm{OH}^{-}$, which increase the difficulty of phenol ions diffusion and so the chances of their adsorption decrease.

\section{Effect of agitation speed}

Figure 10 shows the effect of agitation speed on the rate of adsorption of phenol by MWCNTs. This factor was studied by varying the speed of agitation from 30 to $230 \mathrm{rpm}$, it is observed that by increasing the speed of agitation speed to 130 rpm the percentage removal of phenol increased, then the rate of adsorption becomes constant afterwards. It is obvious that agitation facilitates appropriate contact between adsorbents binding sites and ions in the solution and thus helps the phenol ions to transfer to the carbon Active sites and makes the diffusion of phenol on the surface of MWCNTs much better.

\section{Effect of dose of adsorbent}

One of the most important factors is the adsorbent amount in the water, which affects the capacity of adsorption. We carried out the experiments using different amounts of MWCNTs from 10 to 500 $\mathrm{mg}$, and $\mathrm{pH} 7$, contact time $2 \mathrm{~h}$ and agitation speed $130 \mathrm{rpm}$. Figure 11 shows that with the increase in adsorbent doses up to $300 \mathrm{mg}$, there is an increase in adsorption capacity, then for the remaining dose, the range of adsorption is almost constant, which is due to the presence of abundant sites for ions exchangeable at high dose of adsorbents. While, after certain dose, $300 \mathrm{mg}$, there is no effect on the percentage of the removal.

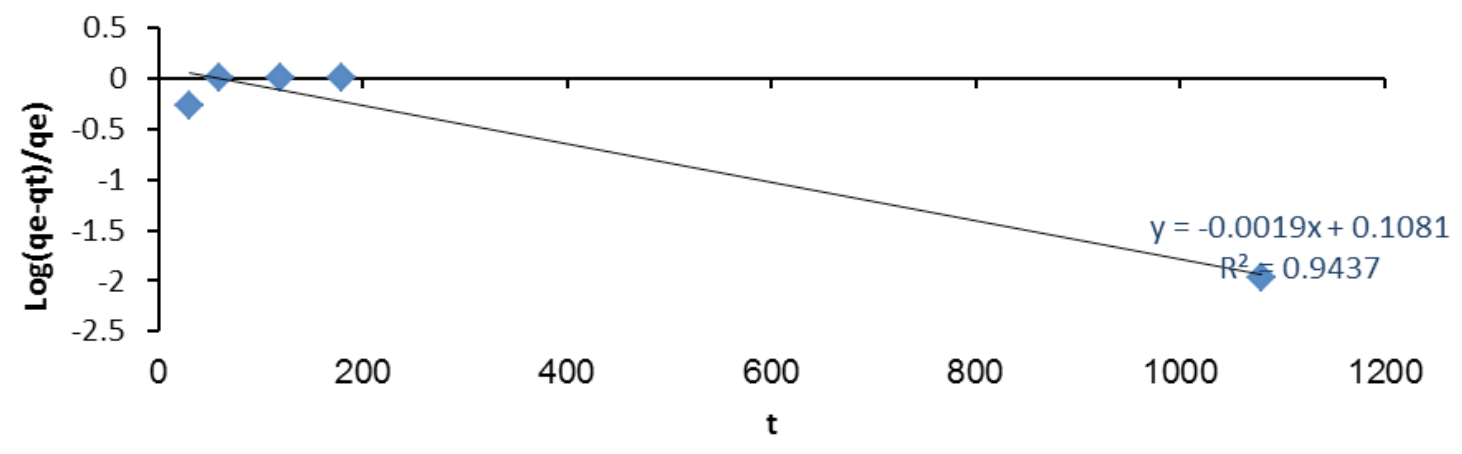

Fig. 7. Pseudo 1st order.

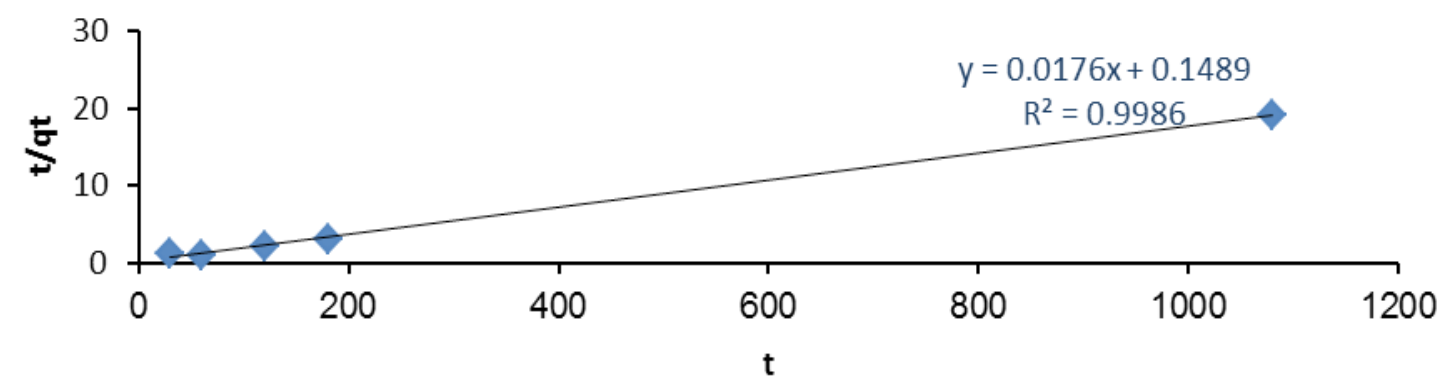

Fig. 8. Pseudo 2nd order.

TABLE 1. The kinetic parameters for the adsorption of phenol on MWCNTs.

\begin{tabular}{|c|c|c|c|c|c|c|c|c|c|}
\hline \multirow{2}{*}{ Compound } & \multicolumn{2}{|c|}{ Pseudo 1 $^{\text {st }}$ order } & \multicolumn{2}{|c|}{$\mathbf{1}^{\text {st }}$ order } & \multicolumn{3}{|c|}{ Pseudo 2 $^{\text {nd }}$ order } & \multicolumn{2}{|c|}{$\mathbf{2}^{\text {nd }}$ order } \\
\cline { 2 - 10 } & $\mathbf{R}^{2}$ & $\mathbf{K}_{\mathrm{p} 1}$ & $\mathbf{R}^{2}$ & $\mathbf{K}_{1}$ & $\mathbf{R}^{2}$ & $\mathbf{q}_{\mathbf{e}}$ & $\mathbf{K}_{\mathrm{p} 2}$ & $\mathbf{R}^{2}$ & $\mathbf{K}_{2}$ \\
\hline \multirow{2}{*}{ MWCNTs } & 0.1486 & 0.00322 & 0.9437 & 0.2489 & 0.9986 & 56.8181 & 0.00208 & 0.3922 & 0.0036 \\
& & & & & & & & & \\
\hline
\end{tabular}

Egypt. J. Chem. 61, No. 1 (2018) 
TABLE 2. The isotherm parameters for the adsorption of phenol on MWCNTs.

\begin{tabular}{|r|c|c|c|c|c|c|}
\hline Adsorbent & \multicolumn{3}{|c|}{ Langmuir } & \multicolumn{3}{c|}{ Freundlich } \\
\hline \multirow{2}{*}{ MWCNTs } & $\mathbf{q}_{\mathbf{m}}$ & $\mathbf{b}$ & $\mathbf{R}^{\mathbf{2}}$ & $\mathbf{n}$ & $\mathbf{k f}$ & $\mathbf{R}^{\mathbf{2}}$ \\
\cline { 2 - 7 } & 56.90 & 103.8367 & 0.9991 & -1.4583 & 0.3649 & 0.9988 \\
\hline
\end{tabular}

\section{Conclusions}

In this study, the influence of different parameters; contact time, agitation speed, $\mathrm{pH}$ of solution and the dose of adsorbent (MWCNTs), was studied to determine their effect on the percentage of removal of phenol from water. It was clear that the removal of phenol in solution increased continuously with increasing $\mathrm{pH}$ from 3 to 7 , while decreased for $\mathrm{pH}$ from 7 to 10 . The maximum percentage of phenol removal at pH 7 by MWCNTs is approximately 51\%. For agitation speed, the removal of phenol increased with increasing the speed up to $130 \mathrm{rpm}$, and then the rate of adsorption remains constant afterwards. Agitation helps good contact between the adsorbents binding sites and ions in the solution so support the phenol ions transfer to the active sites of carbon in MWCNTs.

For the contact time, the removal rate of phenol was about $58 \%$ and the rate of adsorption reach equilibrium after 2 hours.

Finally, with increasing dose of adsorbent up to $300 \mathrm{mg}$, the capacity of adsorption increase and is almost constant for the remaining dose range.

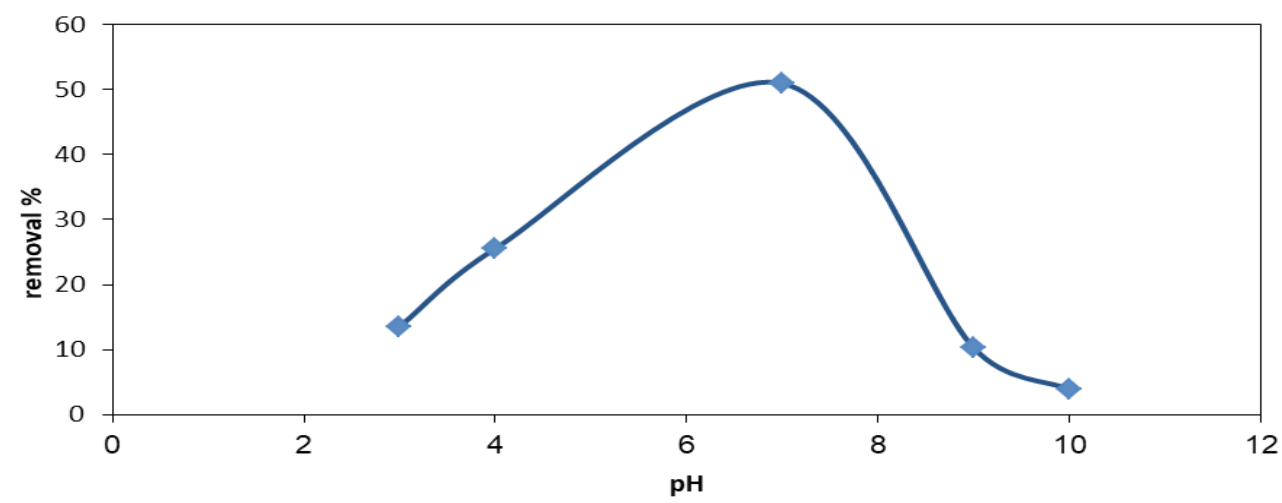

Fig. 9. The effect of $\mathrm{pH}$ on the adsorption of phenol.

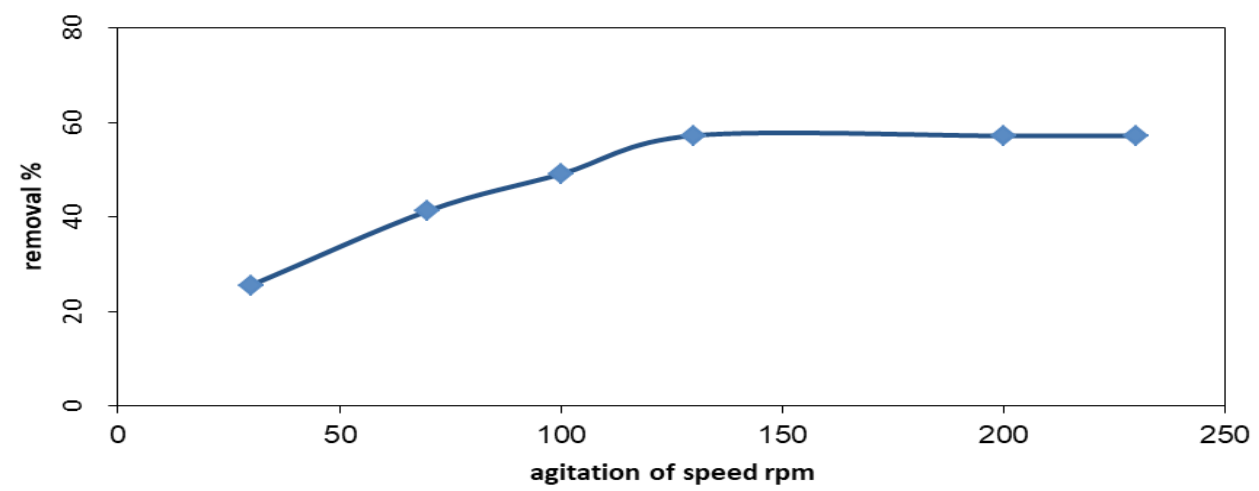

Fig. 10. The effect of agitation speed on the adsorption of phenol. 


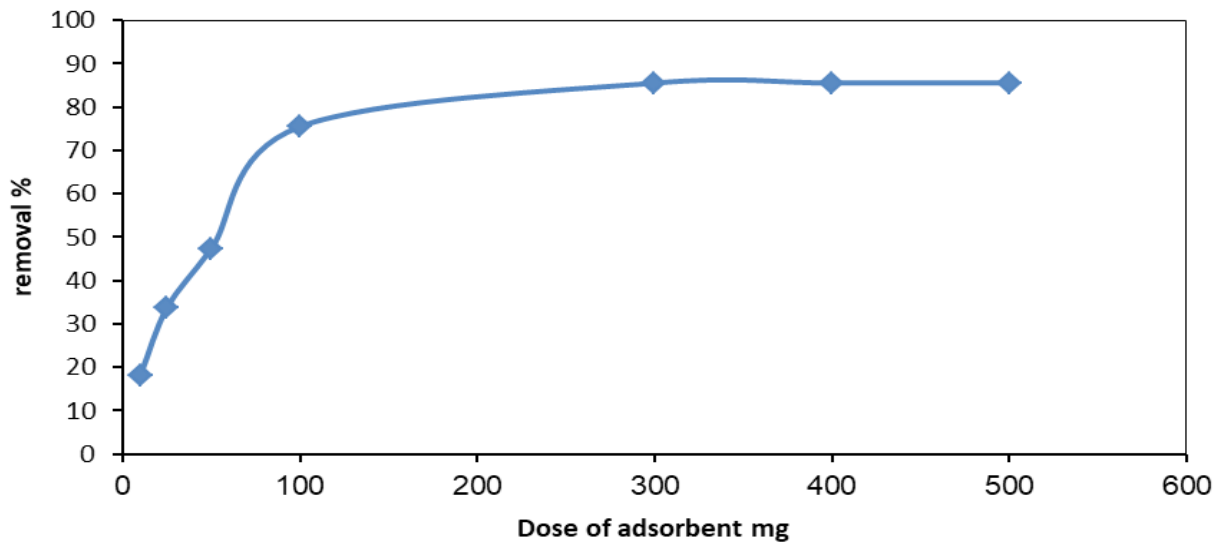

Fig. 11. The effect of dose of adsorbent on the adsorption of phenol.

\section{References}

1. Alebrahim M.F., Khattab I.A., Cai Q. and Sanduk M., Practical study on the electrochemical simultaneous removal of copper and zinc from simulated binarymetallic industrial wastewater using a packed-bed cathode, Egyptian journal of petroleum, 26, 225234 (2017).

2. Mittal A., Krishnan L. and V.K., Use of waste materials-bottom ash and de-oiled soya, as potential adsorbents for the removal of amaranth from aqueous solutions, J. Hazard . Mater., 117, 171-178 (2005)

3. Ahmaruzzaman M., Adsorption of phenolic compounds on low-cost adsorbents: A review, $A d v$. Colloid Interface Sci. 143, 48 (2008).

4. Ahmaruzzaman M. and Gayatri S.L., Activated neem leaf: a novel adsorbent for the removal of phenol, 4-nitrophenol, and 4-chlorophenol from aqueous solutions, J. Chem. Eng. Data, 56, 3004 (2011).

5. Huang J., Jin X. and Deng S., Phenol adsorption on an $\mathrm{N}$ - methylacetamide-modified hypercrosslinked resin from aqueous solutions, Chem. Eng. J., 192, 192 (2012).

6. C.R. Ispas, M.T. Ravalli, A. Steere, S. Andreescu, Multifunctional biomagnetic capsules for easy removal of phenol and bisphenol A., Water Res., 44, 1961 (2010).

7. Guan Z., Liu L., He L. and Yang S. , Amphiphilic hollow carbonaceous microspheres for the sorption of phenol from water. J. Hazard. Mater, 196, 270 (2011).

Egypt. J. Chem. 61, No. 1 (2018)
8. Fierro V., Torne'-Ferna'ndez V., Montane' D., and Celzard A., Removal of phenols from water and petroleum industry refinery effluents by activated carbon obtained from coconut coir pith. Microporous Mesoporous 581 Mater, 111, 276 (2008)

9. Yan J.H., Du C. M., Li X. D., Sun X. D., Ni M.-J., Cen K. F. and Cheron B., Dynamic and spectroscopic characteristics of atmospheric gliding arc in gas-liquid two-phase flow, Plasma Sources Sci. Technol., 14, 637 (2005).

10. Kumar A., Kumar S. and Kumar S., Biodegradation kinetics of phenol and catechol using Pseudomonas putida MTCC 1194. Biochem. Eng. J., 22, 151 (2005).

11. Lin S. H. and Juang R. S., Adsorption of phenol and its derivatives from water using synthetic resins and low-cost natural adsorbents: A review. k Manage., J. Environ. 90, 1336 (2009).

12. Yu J.G., Zhao X.H., Yu L.Y., Jiao F.P., Jiang J.H. and Chen X.Q., Removal, recoveryand enrichment of metals from aqueous solutions using carbon nanotubes, J. Radioanal. Nucl. Chem. 299, 11551163 (2014).

13. Delgado L.F., Charles P., Glucina K. and Morlay C., The removal of endocrine disrup-ting compounds, pharmaceutically activated compounds and cyanobacterial toxins during drinking water preparation using activated carbon-a review, Sci. Total Environ., 435, 509-525 (2012).

14. Min G., Wang S., Zhu H., Fang G. and Zhang Y., Multi-walled carbon nanotubes assolid-phase 
extraction adsorbents for determination of atrazine and its prin-cipal metabolites in water and soil samples by gas chromatography-massspectrometry, Sci. Total Environ., 396, 79-85 (2008).

15. Park J.H., Yoon K.Y., Na H., Kim Y.S., Hwang J., Kim J. and Yoon Y.H., Fabrica-tion of a multiwalled carbon nanotube-deposited glass fiber air filter for theenhancement of nano and submicron aerosol particle filtration and additionalantibacterial efficacy, Sci. Total Environ., 409, 4132-4138 (2011).

16. Xu J., Sheng T., Hu Y., Baig S.A., Lv X. and Xu X., Adsorption-dechlorination of 2,4-dichlorophenol using two specified MWCNTs-stabilized $\mathrm{Pd} / \mathrm{Fe}$ nanocom-posites, Chem. Eng. J., 219, 162-173 (2013).

17. Yang W., Lu Y., Zheng F., Xue X., Li N. and Liu D., Adsorption behavior and mech-anisms of norfloxacin onto porous resins and carbon nanotube, Chem. Eng. J., 179, 112-118 (2012).

18. Yang S., Guo Z., Sheng G. and Wang X., Investigation of the sequestration mecha-nisms of Cd(II) and 1-naphthol on discharged multi-walled carbon nanotubesin aqueous environment, Sci. Total Environ., 420 214-221 (2012).

19. Wang S., Ng C.W., Wang W., Li Q. and Hao Z., Synergistic and competitive adsorptionof organic dyes on multiwalled carbon nanotubes, Chem. Eng. J., 197, 34-40 (2012).

20. Iijima S. and Ichihashi T., Single-shell carbon nanotubes of 1-nm diameter, Nature. 363, 603-605 (1993).

21. Bahgat M., Farghali A.A., El Rouby W.M.A., Khedr M.H. and Anal J., Decoration of MWCNTs with $\mathrm{CoFe} 2 \mathrm{O} 4$ nanoparticles for methylene blue dye adsorption. Appl. Pyrolysis., 92,307-313 (2011).
22. Alstrup K., Bøgelund J., Jackson P., Raun N., Birkedal R., Clausen P., Saber A., Wallin H. and Vogel U., Carbon nanotubes, The Danish Environmental Protection Agency Strandgade 29 DK-1401 Copenhagen K, ISBN no. 978-87-9335298-8 (2015).

23. Stamatin I., Morozan A., Dumitru A., Ciupina V., Prodan G., Niewolski J. and Figiel H., The synthesis of multi-walled carbon nanotubes (MWNTs) by catalytic pyrolysis of the phenolformaldehyde resins, Phys. E Low-Dimension. Syst. Nanostructures, 37, 44-48 (2007).

24. Shieh Y.-T. and Yang Y.-F., Significant improvements in mechanical property and water stability of chitosan by carbon nanotubes, Eur. Polym. J., 42, 3162-3170 (2006).

25. Demirbas E., Kobya M., Senturk E., Ozkan T., Biosorption of chromium from aqueous solution by Gracilaria corticata (Red Algae) and its statistical analysis using response surface methodology. Water SA 30, 533- 539 (2004).

26. Yang W., Ding P., Zhou L., Yu J., Chen X., Jiao F., Preparation of diamine modified mesoporous silica on multi-walled carbon nanotubes for the adsorption of heavy metals in aqueous solution. Appl. Surf. Sci., 282, 38-45 (2013).

27. El Qada E.N., Allen S.J. and Walker G.M., Surface modification effects on CNTs adsorption of methylene blue and phenol. Chem. Eng. J., 124, 103-110 (2006).

(Received 2/10/2017; accepted 5/12/2017) 


\section{أنابيب الكربون النانوية كمادة ماصة فائقة لإزالة الفينول من مياه الصرف الصناعى

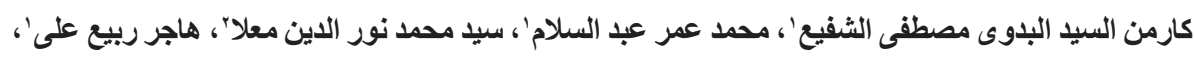

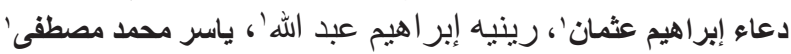 \\ 'معهد بحوث البترول ـ القاهرة - مصر بـ كلية العلوم - جامعة بورسعيد - بور سعيد - مصر.}

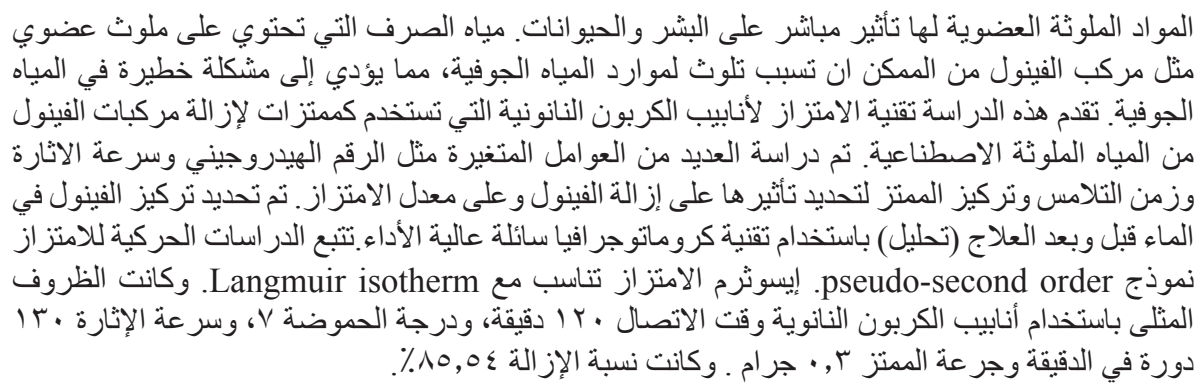

